\section{Psychometric characteristics of an adapted measure of innovative behavior at work}

\author{
Ana Veloso ${ }^{1}$ \\ Hugo Roque ${ }^{1}$ ii \\ Ana Teresa Ferreira ${ }^{2}$ (ID \\ Jorge Gomes ${ }^{3}$
}

\section{Abstract}

Purpose - The objective of this study is to test the psychometric properties of a self-reported measure of innovative behavior in the workplace, the Innovative Work Behavior (IWB) questionnaire, in Portuguese.

Design/methodology/approach - Two studies were carried out (one longitudinal and the other cross-sectional), based on the application of the questionnaire at two moments with an interval of 6 months in between (study I and study II). A longitudinal study was chosen, that is, the data were collected at two different moments, to reduce the most common biases. The Statistical Package for the Social Sciences (SPSS, ver. 26.0) and Analysis of Moment Structures (SPSS AMOS, ver. 22.0) were used.

Findings - The results of the two studies converge to a robust factor solution with one factor. The overall fit indices recorded for the model are quite robust, proving their quality in adjusting to the empirical data $(2 /$ degrees of freedom $=$ 32.8; $\mathrm{CFI}=0.966 \mathrm{GFI}=0.970)$.

Originality/value - The IWB questionnaire is a fast, useful, and efficient measure to gauge innovative potential in the workforce, so its practical advantages are relevant and important. On a practical level, it is important to emphasize that evaluating the innovative behavior of employees can give important clues about the capacity of the organization/employer to foster innovation.

Keywords - innovative behavior, work, innovation, confirmatory factor analysis

1. University of Minho, CICS. Nova, School of Psychology, Department of Applied Psychology, Braga, Portugal

2. CISAS, School of Technology and Management, Polytechnic of Viana do Castelo, Viana do Castelo, Portugal

3. University of Lisbon, ISEG Lisbon School of Economics \& Management, Lisbon, Portugal

\section{How to cite:}

Veloso, A., Roque, H., Ferreira, A. T., Gomes, J. (2021). Psychometric characteristics of an adapted measure of innovative behavior at work. Revista Brasileira de Gestão de Negócios, 23(1), p.141-152.
Received on:

06/18/2018

Approved on:

08/17/2020

Responsible Editor:
Profa. Dra. Gina Gaio

Evaluation process:

Double Blind Review

\section{Reviewers:}

Catarina Brandão; José Carlos Pinho; Carla Freire.

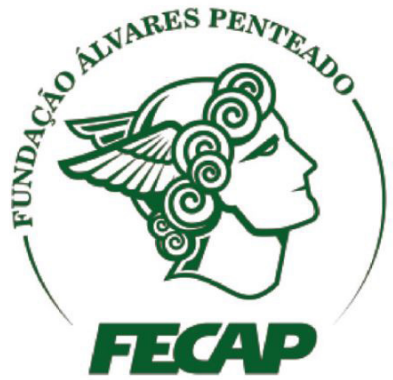

Revista Brasileira de Gestão de Negócios

https://doi.org/10.7819/rbgn.v23i1.4093 


\section{Introduction}

Creativity and innovation are essential to organizations (Gomes, Rodrigues, \& Veloso, 2015; Rodrigues \& Veloso, 2013) and allow them to adapt to constantly changing contexts (Sanders \& Shipton, 2012). Organizations, regardless of the sector in which they operate, have made intentional efforts to promote (Araújo, Silva, \& Brandão, 2015; Teixeira \& Santos, 2016) and effectively manage the ideas and suggestions of their workers (Anderson, Potočnik, \& Zhou, 2014). It is essential to provide professionals with tools that can assist them in the management of internal innovation processes, such as reliable measures of innovative behaviours (De Jong \& Den Hartog, 2010; Stoffers, Van der Heijden, \& Jacobs, 2018).

The objective of this study is to evaluate the psychometric properties of one measure of innovative behaviour in the workplace, the Innovative Work Behaviour (IWB) questionnaire (Scott \& Bruce, 1994), for the Portuguese language. For this purpose, the reliability and construct validity of the scale were estimated using exploratory and confirmatory factor analysis. The IWB questionnaire is a relevant, brief and free instrument that can help evaluate innovative behaviour in the workplace.

\section{Innovative Behaviour}

The literature on creativity is based on the premise that creativity entails the production of new and useful ideas (Mumford \& Gustafson, 1988) and that it is distinct from innovation since the latter represents the adoption, implementation and operationalization of useful ideas (Kanter, 1988; Van de Ven, 1986). Innovation may also include the organization's adaptation of external products or processes, which may be technological or administrative. Some authors even refer to innovation as organizational because it focuses on the development of new organizational forms or practices (Seeck \& Dieehl, 2017). In this study, and according to Jansen (2003), innovative behaviour is all behaviour within the scope of the function performed that intentionally leads to new ideas and to their promotion and implementation for the benefit of the organization for which the individual works.

Innovative behaviour emphasizes the individual action of a worker who initiates and intentionally introduces new and useful ideas related to products, services, processes and procedures in the context of his or her function, group or organization (De Jong \& Den Hartog, 2010). Innovative behaviours arise from the interaction of multiple factors, such as an appropriate organizational climate, supportive leadership, support from co-workers or the willingness of workers (Jansen, 2003, 2005; Sanders \& Shipton, 2012) and the characteristics of the function performed (e.g., autonomy) (Orth \& Volmer, 2017). They can occur at different levels: individual, group or organizational (Andersonet al., 2014). At the individual level, and according to the social interaction approach, innovative behaviour is directly influenced by leadership, the work relationships of the team and the individual's problem-solving style, and it is indirectly influenced by workers' perceptions of the innovation climate of the organization in which they work (Scott \& Bruce, 1994, p.581). Specifically, and reflecting both the original idea of the model's authors and later developments (Orth \& Volmer, 2017), innovative behaviour reflects the behaviours of an individual that result from (1) generating ideas or supporting the ideas of others, (2) gathering the elements necessary for implementation (e.g., funds, schedules, etc.) and (3) perceiving one's ability to innovate.

The model of Scott and Bruce (1994), which guides the development of this survey, adopted a sociopolitical or social interaction approach, as Janssen (2005) later characterized it, revealing the fact that an innovative worker has to act by influencing others; seeking information, resources and support from supervisors; and adopting intuitive and non-systematic problem-solving models that break with the formal processes of the organization. The model is organized around four dimensions, as previously mentioned: leadership, work group, individual problem-solving styles and the innovation climate of the organization. According to the authors, these four dimensions interact dynamically, and individual intuitive problem-solving styles have a direct impact on individual innovative behaviour, i.e., information processing using different unconventional approaches and methodologies within the organization. The remaining dimensions result from individuals' perceptions of leadership, including the interactions between leaders and subordinates and the latter's expectations of the role of management; their perceptions of peer interactions within the work group; and finally, their perceptions of the innovation climate, which translates into organizational support for innovation and the availability of resources.

Innovative behaviour is defined by these authors as the participation of an individual in one or more 
phases of the innovative process. This participation translates into (1) the recognition of a problem and the generation of ideas or solutions, whether original or adapted (creativity); (2) the search for sponsors for the solution found (promotion); and (3) the implementation of the solution (implementation) (Scott \& Bruce, 1994). Given this conceptualization of innovative behaviour, it can be concluded that the questionnaire being studied provides a one-dimensional evaluation of the concept under study. This article focuses on evaluating the psychometric characteristics of a self-reported measure of innovative behaviour in the workplace, the IWB questionnaire, in Portuguese.

The relevance of this article is related to the need to develop a psychometrically valid measure in Portuguese that is easy to use in the organizational context. This instrument is a quick, useful and efficient measure of innovative potential in the workforce.

\section{Method}

This article presents a longitudinal and cross-sectional study based on the application of the questionnaire at two points in time with an interval of 6 months in between (study I and study II). A longitudinal design was adopted; i.e., the data were collected at two different times, which can reduce the most common biases.

\section{I. Procedure and sampling}

A non-probabilistic convenience sample was used. The questionnaire was applied to workers from three different types of organizations to avoid biases from using a single source (Podsakoff, MacKenzie, Lee, $\&$ Podsakoff, 2003). The organizations involved in the study were selected by convenience and operate within the primary health care, new technologies and industrial/ agricultural sectors in Portugal. In the health organizations, the questionnaires were applied again using a physical format after a 6-month period. Although we used a convenience sample and sought to increase its variability, we tried to obtain data from three different industries with predictably different levels of innovative behaviour among their workers: in the new technologies sector, the incentive for innovation is probably very high, while in agriculture and industry, it is likely to be lower, and in primary health care, a moderate level of incentive for innovation is expected. The organizations were contacted, and the questionnaires were applied in digital and physical formats by the researchers. Given the non-probabilistic sample, we followed the suggestion of Tabachnick and Fidell (2007), who consider, as a general rule, a minimum of 300 cases for a factor analysis.

In all of the organizations involved, the relevant organizational decision-making bodies were asked to authorize the study, and each participant was individually asked to sign an informed consent form in accordance with the Declaration of Helsinki and the Oviedo Convention.

The sample for study I consisted of 464 workers aged between 27 and 64 years old, with a mean age of 43.57 $(S D=10.25)$. A total of $354(76.6 \%)$ participants were female. Ninety-seven $(21.0 \%)$ participants had worked at the same organization for less than 2 years, 320 (69.3\%) had worked at the same organization for between 2 and 7 years, and $47(9.7 \%)$ had worked at the same organization for more than 7 years. Study I was longitudinal; therefore, the IWB questionnaire was applied again after 6 months, and the dropout rate was $66.6 \%$. The sample for study II consisted of 456 workers aged between 22 and 64 years old, with a mean age of $37.55(\mathrm{SD}=6.59)$. One hundred and eighty-one (39.8\%) participants were female. One hundred and nineteen (26.2\%) participants had worked in the same organization for less than 2 years, 137 (30.2\%) had worked in the same organization for between 2 and 7 years, and 200 (43.6\%) had worked in the organization for more than 7 years.

\section{$3 \cdot 2$ Instrument}

The questionnaire was developed based on the studies by Kanter (1988) and Scott and Bruce (1994) with research and development professionals. In the study by Scott and Bruce (1994), the managers evaluated the innovative behaviour of each of their subordinates, considering the three levels of innovation identified by Kanter (1988): idea generation, idea promotion and idea implementation. Janssen $(2000,2005)$ and Janssen and Van Yperen (2004) used an adapted version of the questionnaire to collect the perceptions of workers and supervisors. They indicated three reasons for the adoption of self-report measures: (1) the workers' perceptions of their own behaviours and the constraints they face are more insightful than those of their supervisors; (2) performance evaluation, specifically in the case of innovative behaviours, is susceptible to interpretation and therefore varies among evaluators; and (3) supervisors may not have access to all of the innovative behaviours of their employees and can only identify those that are intentionally presented to them. Given these factors and 
the need to reformulate the questionnaire for the direct application to employees who do not have management functions, the original instrument was transformed into a self-report measure (e.g., "is innovative" was changed to "I am an innovative person"). Additionally, adjustments were made without changing the underlying conceptual structure to allow the measure to focus on evidence of behaviours within the scope of the innovation process described by Kanter (1988), as previously mentioned: idea generation, promotion and implementation. The questionnaire was translated into Portuguese and then independently backtranslated into English; the back-translation revealed no distortions in the meanings of the items compared to the original English version. The items, in addition to being translated, were changed to the first person and rephrased to make them more concrete and intelligible (e.g., "I am an innovative person" was reformulated to "I am an innovative person (who seeks to put their ideas into practice)"). The original instrument consisted of 6 items and a single dimension. The items are evaluated on a 6-point Likert scale where 1 = strongly disagree, 2 = disagree, 3 = partially disagree, $4=$ partially agree, $5=$ agree and $6=$ strongly agree. Only one item, "I am an innovative person", was removed because we considered it repetitive. To test external validity, two other measures were used in the study, namely, Total Commitment by Nascimento, Lopes and Salgueiro (2008) and Global Human Resource Management by Veloso, Roque and Ferreira (2016).

\subsection{Statistical analyses}

The first study investigated the underlying factor structure and homogeneity of the items in each of the scales through exploratory factor analysis (EFA, principal axis factoring method). In this first study, reliability was also assessed through an indicator of internal consistency (Cronbach's alpha), and test-retest reliability was assessed through the intraclass correlation coefficient (Hair, Black, Babin, \& Anderson, 2010).

In the second study, structural equation modelling was used, namely, confirmatory factor analysis (CFA, maximum likelihood method) with AMOS software (v 22 SPSS, Inc., Chicago, IL), as described by Maroco (2010), was used to evaluate the psychometric qualities of the evaluation model. The univariate and multivariate skewness and kurtosis coefficients and the existence of outliers were analysed using the Mahalanobis square distance. The overall goodness-of-fit of the factor model was determined according to the indices and respective reference values described by Maroco (2010) and by
Fornell and Larcker (1981), namely, $\chi^{2} / \mathrm{df}, \mathrm{CFI}, \mathrm{GFI}$, RMSEA, $P$ [rmsea $\leq 0.05]$ and MECVI. The local goodnessof-fit was determined based on the modification indices (greater than 11; $\mathrm{p} \leq 0.001$ ) produced by AMOS and on theoretical considerations. In the tests used, results with a significance value lower than $0.05(\mathrm{p}<0.05)$ were considered statistically significant. NFI, CFI and TLI values $\geq 0.95$ are considered very good, and the closer the RFI is to 1, the better it is (Byrne, 2001; Hair et al., 2006; Tanaka, 1993; Yu, 2002).

The composite reliability and the average variance extracted per factor were evaluated as described by Fornell and Larcker (1981). We considered population-based fit indices that compare the fit of the model obtained with the means, sample variances and values that would be obtained from the population.

The external validity of the measure was evaluated by comparing it with two duly validated and recognized measures, namely, Total Commitment by Nascimento et al. (2008) and Global Human Resources Management by Veloso, Roque and Ferreira (2016).

Our analytical rationale began with an EFA to evaluate/explore the factor structure, since the original scale was not a self-report scale. We followed Hair et al. (2006) and Tabachnick and Fidell (1989) in the statistical analysis process. Based on our research objective, we considered EFA the most appropriate choice. Still, according to Cabrera-Nguyen (2010), EFA should be conducted first, and then a CFA should be conducted using a different sample (or samples) to evaluate the EFA theory informed a priori by the factor structure and the psychometric properties of the measure. Study II was thus conducted to strengthen the evidence of study I.

To build the databases and conduct the statistical analyses, the Statistical Package for the Social Sciences (SPSS, ver.: 26.0) and the Analysis of Moment Structures (SPSS AMOS, ver. 22.0) were used.

\section{Results}

The external validity (Table 1 ) of the measure was evaluated by comparing it with two duly validated and recognized measures, namely, Total Commitment by Nascimento et al., (2008) and Global Human Resources Management by Veloso, Roque and Ferreira (2016).

The evaluated dimensions showed significant correlations at the same level $(\mathrm{p}<0.001)$. All dimensions correlated with those measured in the IWB, demonstrating its external validity, and no correlation was $\geq 0.90$. The results show good correlation and external validity (Maroco, 2010). 


\section{I Study I}

The analysis of the correlation matrix (Table 2) showed significant correlations $(\mathrm{p} \leq 0.001)$, with values between $r=0.38$ and $r=0.68$ and a determinant of 0.145 . There was no multicollinearity or singularity (Field, 2005).

In this first study, criteria were established for the retention of items in each of the scales: (1) saturation $\geq 0.40$ for each item in the hypothetical factor, and only in a single factor; (2) final factor solution explains at least $50 \%$ of the total variance; (3) coherence between the factor solution and the items that constitute each factor; and (4) each factor is represented by at least 3 items (Costello \& Osborne, 2005; Field, 2005). No items were removed.

The commonality analysis (Table 3 ) revealed values between 0.28 and 0.65 , with a mean of 0.52 , thus indicating that $52 \%$ of the variance associated with the items is common or shared. The factorability of the data matrix was observed, with a $\mathrm{KMO}$ value greater than $0.60(\mathrm{KMO}=0.83)$, and the Bartlett's sphericity test was significant $(\mathrm{p}<0.001)$. EFA was used through the principal axis factoring method with orthogonal rotation (varimax procedure). The inflection points in the scree plot (Figure 1) and the eigenvalues were analysed,

Table 1

\section{External validity}

\begin{tabular}{lccccc}
\hline & Average & $\begin{array}{c}\text { Standard } \\
\text { deviation }\end{array}$ & $\mathbf{N}$ & (1) & (2) \\
\hline (1) IWB & 4.48 & 0.71 & 449 & - & (3) \\
(2) Global Human Resources Management & 5.15 & 1.13 & 455 & $\mathbf{0 . 2 0}^{* *}$ & - \\
(3) Total Commitment & 5.41 & 0.89 & 416 & $\mathbf{0 . 1 8}^{* *}$ & $\mathbf{0 . 4 5 ^ { * * }}$ \\
\hline
\end{tabular}

Note. Values in the diagonal (in bold) represent significant correlations at $\mathrm{p}<0.001$

Table 2

\section{Correlation matrix of the IWB}

$\begin{array}{lllll}\text { Item } 1 & \text { Item } 2 & \text { Item } 3 & \text { Item } 4 & \text { Item } 5\end{array}$

I often present creative ideas (new and useful ideas).

I promote and support the ideas of others.

$0.44^{* * *}$

I seek and obtain the funds needed to implement new ideas.

$0.54^{* * *} \quad 0.40^{* * *}$

I develop appropriate plans and schedules to implement new ideas. $\quad 0.58^{* * *} \quad 0.40^{* * *} \quad 0.68^{* * *}$

I am an innovative person (who seeks to put their ideas into practice). $\begin{array}{lllll}0.60^{* * *} & 0.38^{* * *} & 0.49^{* * *} & 0.55^{* * *}\end{array}$

${ }^{* * *} \mathrm{p} \leq 0.001$

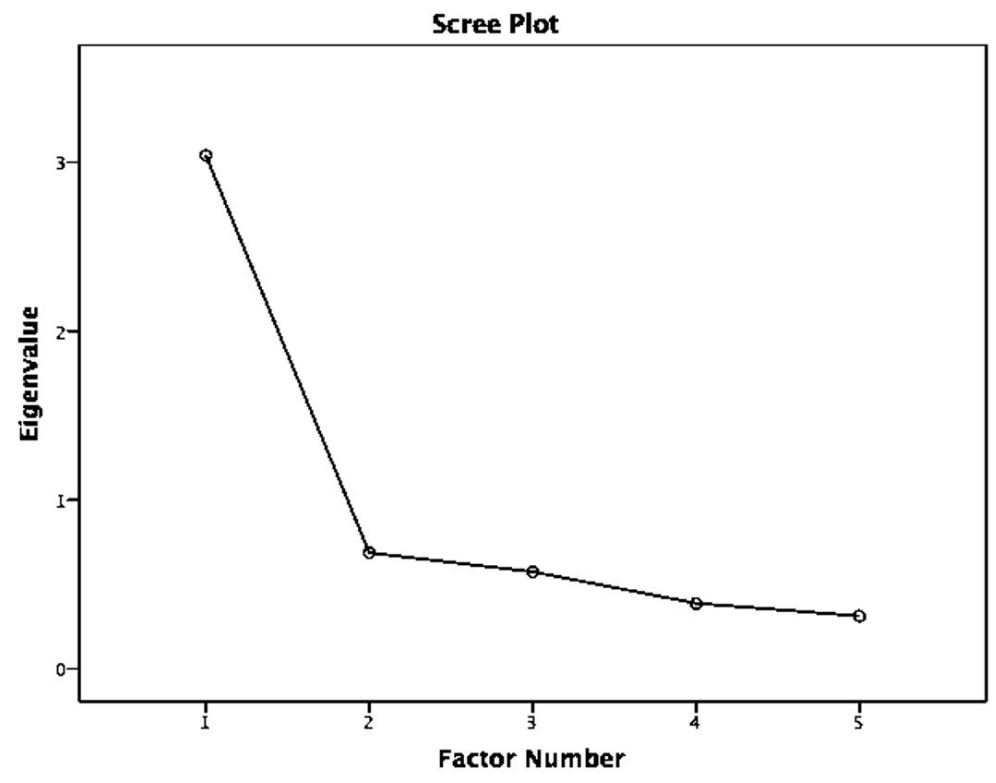

Figure 1 - Scree plot and eigenvalues suggesting a one-factor solution 
which led to the extraction of a single factor. The scree plot indicated that no more than one factor should be extracted, and the one-factor solution met the Kaiser normalization criterion (eigenvalue $\geq 1$ ). The one-factor solution explained $51.63 \%$ of the total variance. Table 2 shows that the factor loading of item 2 was the lowest; however, it was considered reasonable $(>0.45)$. All other items had a factor loading $>0.71$, which is considered excellent (Field, 2005). The frequencies of each item were analysed, and the full range of scale points was used for each item, showing the frequency of occurrence of different behaviours.

Internal consistency was calculated using the Cronbach's alpha coefficient, and we analysed whether the removal of any item caused changes in the coefficient value. Table 4 shows that the measure had moderate to high reliability (Murphy \& Davidsholder, 1988): $\alpha=0.84$. It was also observed that there was no item that, when removed, considerably increased or decreased the alpha value.

The intraclass correlation coefficients (ICCs) were calculated according to the procedures described by Shrout and Fleiss (1979). The results pointed to average stability across all evaluators; the ICC values for single measures also showed stability for a single idealized evaluator. Considering that the measurement error is lower on average across the total sample, the ICC score for average measures is typically higher than that for single measures. Table 5 presents the ICC values and the ANOVA calculated for the single measures to test $\mathrm{H}_{0}$ (that the scores of the measure at the two evaluation time-points would not be correlated). The ICC values for both cases were above 0.60 , indicating satisfactory stability (Landis \& Koch, 1977).

In summary, the results of the measure confirm its positive psychometric characteristics.

Table 3

\section{IWB factor structure and commonality}

\begin{tabular}{lcc}
\hline & Factor & $\mathbf{h}^{2}$ \\
\hline 1. I often present creative ideas (new and useful ideas). & 0.769 & 0.592 \\
2. I promote and support the ideas of others. & 0.532 & 0.283 \\
3. I seek and obtain the funds needed to implement new ideas. & 0.751 & 0.564 \\
4. I develop appropriate plans and schedules to implement new ideas. & 0.806 & 0.649 \\
5. I am an innovative person (who seeks to put their ideas into practice). & 0.703 & 0.494 \\
Percentage of total variance & 51.63 & \\
\hline
\end{tabular}

Table 4

\section{Reliability}

\begin{tabular}{lcccc}
\hline & n & Mean & SD & $\begin{array}{c}\text { Cronbach's alpha } \\
\text { If the item is } \\
\text { removed }\end{array}$ \\
\hline Item 1 & 464 & 4.43 & 0.93 & 0.79 \\
Item 2 & 464 & 4.98 & 0.69 & 0.84 \\
Item 3 & 464 & 4.24 & 1.06 & 0.80 \\
Item 4 & 464 & 4.31 & 0.95 & 0.78 \\
Item 5 & 464 & 4.52 & 0.93 & 0.81 \\
\hline
\end{tabular}

Table 5

\section{ICC values related to the IWB}

\begin{tabular}{lcccc}
\hline & \multirow{2}{*}{ ICC } & \multicolumn{2}{c}{$\mathbf{9 5 \% \text { confidence interval }}$} & \multirow{2}{*}{ F (154) } \\
\cline { 3 - 4 } & & Lower limit & Upper limit & $4.057^{* * *}$ \\
Single measures & 0.606 & 0.496 & 0.697 & \\
Average measures & 0.755 & 0.663 & 0.821 & \\
\hline
\end{tabular}




\section{$4 \cdot 2$ Study II}

In study II, we can observe from the goodnessof-fit indicators that this model fit the data, differed for the different indicators and can be considered very good $\left(\chi^{2} / 4=5.98, p=0.20 ; \mathrm{CFI}=0.99 \mathrm{GFI}=0.99 ; \mathrm{RMSEA}=0.03\right.$; and MECVI=0.06) (Figure 2). Furthermore, when the population matrix and the estimated matrix were equal, the mean error of the model was minimal (Table 6).

\subsection{Reliability and convergent and discriminant validity}

The composite reliability of the factors (Fornell \& Larcker, 1981) was high, at 0.83 .

Reliability was also assessed by calculating the composite reliability (CR) and maximum reliability (MaxR or H) (Hancock \& Mueller, 2001). Convergent validity was assessed by calculating the average variance extracted
Table 6

\section{Structural model goodness-of-fit indices: maximum likelihood}

\begin{tabular}{lc}
\hline \multicolumn{1}{c}{ Absolute indices } & Model \\
\hline$\chi^{2} / \mathrm{df}$ & 5.98, \\
& $\mathrm{df}=4 ;$ \\
& $\mathrm{p} \leq 0.20$ \\
Standardized root mean square residual (SRMR) & 0.013 \\
Goodness-of-fit index (GFI) & 0.995 \\
Adjusted goodness-of-fit index (AGFI) & 0.980 \\
Relative indices & \\
Normal fit index (NFI) & 0.993 \\
Comparative fit index (CFI) & 0.998 \\
Relative fit index (RFI) & 0.920 \\
Tucker-Lewis index (TLI) & 0.931
\end{tabular}

\section{Population-based fit indices}

Root mean square error of approximation (RMSEA) $\quad 0.033$ PCLOSE

The coefficients of the error variances were moderate and statistically significant $(\mathrm{p}<0.001)$.

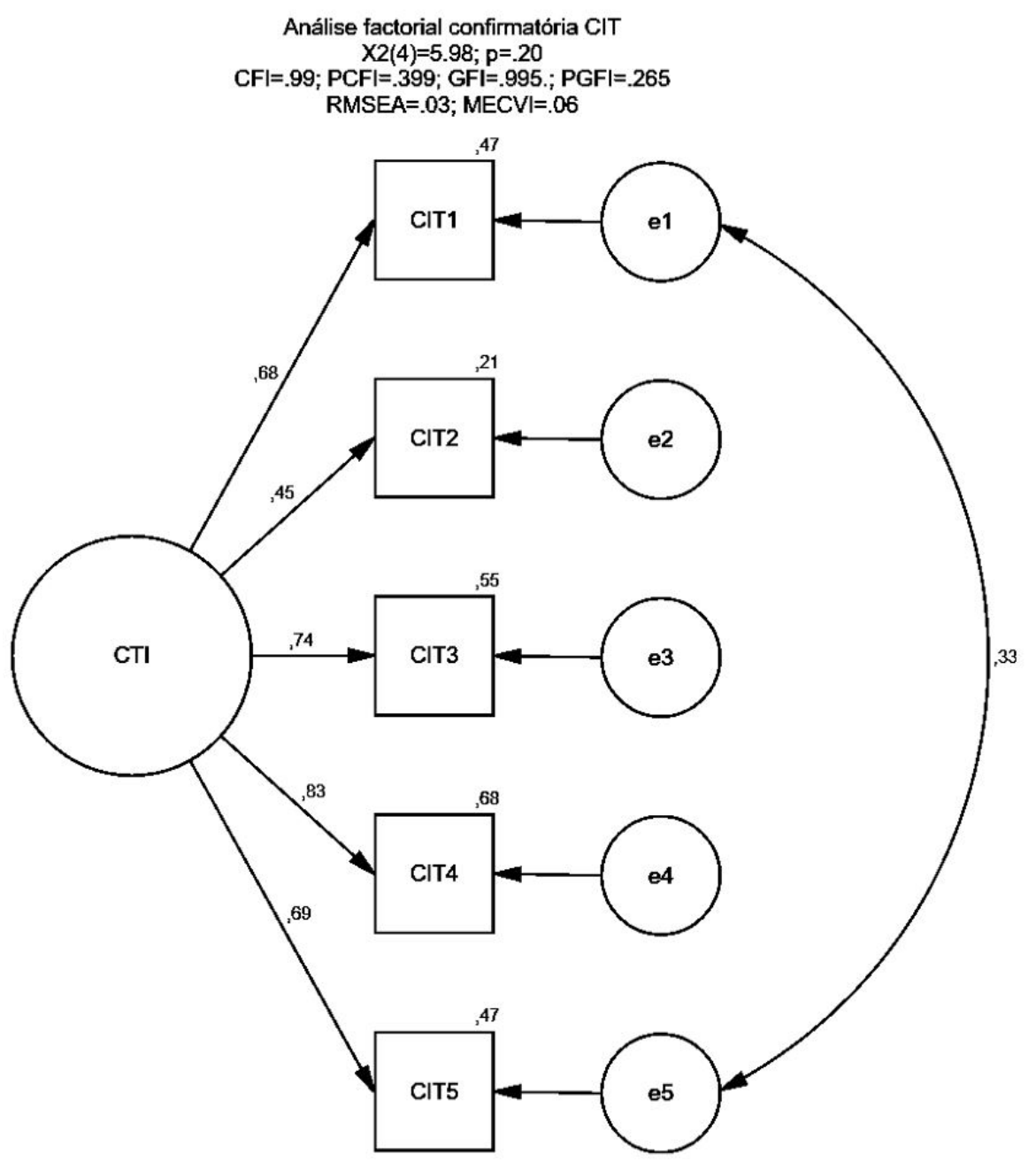

Figure 2. Confirmatory factor analysis of the model 
(AVE) and comparing it with the CR. Discriminant validity should primarily be assessed by calculating the maximum shared squared variance (MSV) and the average shared squared variance (ASV) and comparing these values with the AVE. However, this questionnaire is one-dimensional, which prevented the calculation of the MSV and ASV. The cut-off points recommended by $\mathrm{Hu}$ and Bentler (1999) were used. According to Fornell and Larcker (1981), these cut-off points could be used because they have been referred to as an adequate indicator of convergent validity (Maroco, 2010).

Table 7 shows a $C R$ value $>0.7(C R=0.83)$ and an $\mathrm{H}$ value $>0.8(\mathrm{MaxR}=0.84)$.

Regarding convergent validity (Table 7), $\mathrm{CR}>\mathrm{AVE}$, and the AVE value was greater than $0.5(\mathrm{AVE}=0.53)$. Thus, it is possible to state that this one-dimensional questionnaire has good reliability and convergent validity.

\section{Discussion and Conclusions}

Given the reported results, it can be concluded that the IWB has good psychometric characteristics for use in the Portuguese language and therefore meets its goals of measuring innovative behaviour in the workplace.

This instrument provides professionals and researchers with a way of evaluating innovative behaviour that is both statistically and conceptually valid. We emphasize that the instrument can be used to scrutinize some of the main individual behaviours that characterize the three phases of the innovation process, from the generation of ideas to their promotion and implementation, from the worker's perspective (De Jong \& Den Hartog, 2010; Janssen 2000; Orth \& Volmer, 2017). From a conceptual point of view, the theoretical model underlying the questionnaire was validated, which partially confirms the universality of innovation-oriented behaviours.

On a practical level, it is important to note that, at a time when several Portuguese industries are modernizing and advancing into global markets, the evaluation of the innovative behaviour of employees can provide important clues about the ability of the organization itself to foster innovation. In fact, and according to the basic conceptual model used in the development of this instrument (Scott \& Bruce, 1994), the individual is not solely responsible for the innovation process. Individual innovation behaviours are manifested when there is an organizational climate that favours individual behaviour in the dimensions of leadership, work group and organizational support. If workers exhibit innovative behaviours that are not reflected in the overall performance of the organization, it is up to the organization to intervene in the other dimensions to provide support for innovation.

As mentioned above, this instrument has practical advantages for its users. The five items can be included, for example, in a more general evaluation of the organizational climate or as part of a process for evaluating the potential of employees, thus providing management with an additional tool for observing workers. In addition, understanding how employees perceive their involvement in the innovation process, as conceptualized in the model of Scott and Bruce (1994), allows for the design of organizational interventions that support innovation and its implementation. The questionnaire can also be included in the recruitment and selection processes of research and development departments to better select employees that are naturally oriented towards innovative behaviours. However, the use of the IWB for human resources management in this context requires a more in-depth analysis in the future as this was not the main purpose of this study. Finally, this brief scale can be used in organizational change processes that seek to encourage and stimulate creativity and innovation in the work environment because, by showing behaviours that should be included in the innovative process (idea generation, promotion and implementation), it gives concrete clues about the stages of the process in which to intentionally intervene.

Future research should focus on the convergent and divergent validity of this instrument, especially through the inclusion of other instruments, to continue to

\section{Table 7}

\section{Reliability and convergent and discriminant validity}

\begin{tabular}{cccccc}
\hline & CR & AVE & MSV & ASV & MaxR(H) \\
\hline Total commitment & 0.827 & 0.532 & & 0.840 \\
\hline
\end{tabular}

Note: CR - composite reliability; AVE - average variance extracted; MSV - maximum shared squared variance; ASV - average shared squared variance; $\operatorname{MaxR}(\mathrm{H})$ - maximal reliability 
confirm the factorial purity of the questionnaire. Although we performed some tests to evaluate multicollinearity, considering that this is a unidimensional scale, we suggest that future studies conduct further analyses.

It is important to explore predictive validity as the measurement of more or less innovative behaviours should result in more or less superior group and organizational performance, respectively. In research on the subject, this instrument can be combined with another classic instrument, the Kirton Adaptation-Innovation Inventory (Kirton, 1977), to determine which innovation profiles are more or less related to which innovative behaviours. Further research on innovation and creativity that, for example, correlates indicators of innovative behaviour with relevant organizational variables and examines innovative behaviour as an indicator of individual performance, is important for the development of this area of knowledge. Furthermore, few studies have focused on the impact that human resource management and its practices have on innovation at the individual level and on understanding how to effectively stimulate individual innovative behaviour, thus highlighting the relevance of investing in this area of research (Bos-Nehles \& Veenendaal, 2019; Kim \& Chung, 2017).

\section{Limitations}

Discriminant validity, according to Fornell and Larcker (1981), evaluates whether the items that reflect one factor are correlated with other factors, i.e., whether the factors are distinct (Maroco, 2010). Given the unifactorial dimension of the scale, it was not possible to conduct this analysis. It is important to continue to develop studies with this instrument that test its discriminant validity. This was a non-probabilistic convenience sample, so it was not possible to conduct and develop discriminant validity tests.

Additionally, in this convenience, non-probabilistic sample, it was not possible to track the number of participants, considering that it was a sample of the general population that was collected by convenience in organizations. Therefore, it was not possible to determine whether there were effects on sample selection.

\section{References}

Anderson, N., Potočnik, K., \& Zhou, J. (2014). Innovation and creativity in organizations a state-of-the-science review, prospective commentary, and guiding framework. Journal of Management, 40(5), 1297-1333.

Araújo, G. D., da Silva, A. B., \& Brandão, J. M. F. (2015). O que revela a literatura internacional sobre os vínculos entre aprendizagem, competências e inovação? RAI: Revista de Administração e Inovação, 12(2), 7-37.

Bos-Nehles, A. C., \& Veenendaal, A.A.R. (2019). Perceptions of HR practices and innovative work behavior: the moderating effect of an innovative climate, The International Journal of Human Resource Management, 30:18, 2661-2683, DOI: $10.1080 / 09585192.2017 .1380680$.

Byrne, B.M. (2001). Structural equation modeling with AMOS: Basic concepts, applications, and programming. Nova York: Psychology Press.

Costello A, B., \& Osborne J. (2005). Best practices in exploratory factor analysis: Four recommendations for getting the most from your analysis. Practical Assessment, Research \& Evaluation, 10(7),1-9.

Cabrera- Nguyen, P. (2010). Author guidelines for reporting scale development and validation results in the Journal of the Society for Social Work and Research. Journal of the Society for Social Work and Research, 1(2), 99-103. doi/ 10.5243/jsswr.2010.8.

De Jong, J., \& Den Hartog, D. (2010). Measuring innovative work behaviour. Creativity and Innovation Management, 19 (1), 23-36.

Field A. (2005). Discovering statistics using SPSS (2 $\left.{ }^{\text {nd }} E d\right)$. London: Sage.

Fornell, C., \& Larcker, D.F. (1981). Evaluating structural equation models with unobservable variables and measurement error. Journal of Marketing Research, 18(1), 39-50.

Gomes, J.F.S., Rodrigues, A.F. \& Veloso, A. (2015). Creativity at work: The role of context. In H. Shipton, P. Budhwar, P. Sparrow, \& A. Brown (Eds.), Human Resource Management, Innovation and Performance (Cap.18,pp. 282-297). London, Palgrave Macmillan.

Hair, J.F., Black, B., Babin, B., Anderson, R.E., \& Tatham, R.L. (2006). Multivariate data analysis (6th ed.). New York: Upper Saddle River: Pearson 
Hancock, G. R., \& Mueller, R. O. (2001). Rethinking construct reliability within latent variable systems. In. R. Cudek, S. du Toit, D. Sorbom (Eds). Structural equation modeling: Present and future, (Cap.10, pp.195-216). Chicago: Scientific Software International.

Hu, L.-T., \& Bentler, P. M. (1999). Cutoff criteria for fit indexes in covariance structure analysis: Conventional criteria versus new alternatives. Structural equation modeling: a multidisciplinary journal, 6(1), 1-55. doi:10.1080/10705519909540118

Janssen, O. (2000). Job demands, perceptions of effort, reward fairness and innovative work behaviour. Journal of Occupational and Organizational Psychology, 73(3), 287-302. doi:10.1348/096317900167038

Janssen, O. (2003). Innovative behaviour and job involvement at the price of conflict and less satisfactory relations with co-workers. Journal of Occupational and Organizational Psychology, 76(3), 347-364. doi:10.1348/096317903769647210

Janssen, O. (2005). The joint impact of perceived influence and supervisor supportiveness on employee innovative behaviour. Journal of Occupational and Organizational Psychology, 78(4), 573-579. doi.org/10.1348/096317905X25823

Janssen, O., \& Van Yperen, N. W. (2004). Employees' goal orientations, the quality of leader-member exchange, and the outcomes of job performance and job satisfaction. Academy of Management Journal, 47(3),368-384. doi:10.5465/20159587

Janssen, O., Vliert, E., V. de \& West, M. (2004). The bright and dark sides of individual and group innovation: A special issue introduction. Journal of Organizational Behavior, 25(2), 129-145. doi:10.1002/job.242

Kim, J. S. \& Chung, G. H. (2017). Implementing innovations within organizations: a systematic review and research agenda, Innovation, 19(3), 372399,doi:10.1080/14479338.2017.1335943

Kanter, R. M. (1988). Three tiers for innovation research. Communication Research, 15(5), 509-523. doi. org/10.1177/009365088015005001
Kirton, M. J. (1977). Adaptors and innovators and superior-subordinate identification. Psychological Reports, 41, 289-290. doi.org/10.2466/pr0.1977.41.1.289

Landis, J., \& Koch, G. (1977). The measurement of observer agreement for categorical data. Biometrics, 33, 159-174. Doi: $10.2307 / 2529310$

Marôco, J. (2010). Análise de Equaçóes Estruturais: Fundamentos teóricos, Software e Aplicaçóes. Report Number. Portugal.

Mumford, M. D., \& Gustafson, S. B. (1988). Creativity syndrome: Integration, application, and innovation. Psychological bulletin, 103(1), 27. dx.doi.org/10.1037/00332909.103.1.27

Murphy, K. R., \& Davidshofer, C. O. (1988). Psychological testing: Principles and applications. Englewood Cliffs, New Jersey: Prentice Hall.

Nascimento, J. L., Lopes, A., \& Salgueiro, M. F. (2008). Estudo sobre a validação de "Modelo de Comprometimento Organizacional" de Meyer e Allen para o contexto Português. Comportamento Organizacional e Gestäo, 14(1), 115-133.

Podsakoff, P., MacKenzie, S., Lee, J., and Podsakoff, N. (2003), "Common method biases in behavioral research: A critical review of the literature and recommended remedies", Journal of Applied Psychology, Vol. 88 No5, pp. 879-903.

Orth, M., \& Volmer, J. (2017). Daily within-person effects of job autonomy and work engagement on innovative behaviour: The cross-level moderating role of creative self-efficacy. European Journal of Work and Organizational Psychology, 1-12. doi.org/10.1080/1359 432X.2017.1332042

Rodrigues, A. F., \& Veloso, A. (2013). Contribuiçōes da gestâo de recursos humanos para a criatividade e inovação organizacional. Revista Psicologia Organizaçôes e Trabalho, 13(3), 293-308.

Sanders, K., \& Shipton, H. (2012). The relationship between transformational leadership and innovative behaviour in a healthcare context: a team learning versus a cohesion perspective. European Journal of International Management, 6(1), 83-100. doi.org/10.1504/EJIM.2012.044759 
Scott, G.S., \& Bruce, R.A. (1994) Determinants of innovative behavior: a path model of the individual innovation in the workplace, Academy of Management Journal, 37(3), 580-607. doi.org/10.5465/256701

Seeck, H., \& Diehl, M. R. (2017). A literature review on HRM and innovation-taking stock and future directions. The International Journal of Human Resource Management, 28(6), 913-944. doi.org/10.1080/09585 192.2016.1143862

Shrout, P., \& Fleiss, J. (1979). Intraclass correlations: Uses in assessing rater reliability. Psychological Bulletin, 86, 420-428. dx.doi.org/10.1037/0033-2909.86.2.420

Stoffers, J. M., Van der Heijden, B. I., \& Jacobs, E. A. (2018). Employability and innovative work behaviour in small and medium-sized enterprises. The International Journal of Human Resource Management, 1-28. doi.org/1 0.1080/09585192.2017.1407953

Tanaka, J.S. (1993). Multifaceted conceptions of fit in structural equation models. In K.A. Bollen, \& J.S. Long (eds.), Testing structural equation models. Newbury Park, CA: Sage.

Tabachnick, B. \& Fidell, L. (2007). Using multivariate statistics. 5th Edition. Boston, U.S.: Pearson Education.

Teixeira, A. A., \& Santos, L. C. B. D. (2016). Innovation performance in service companies and KIBS vis-à-vis manufacturing: the relevance of absorptive capacity and openness. Revista brasileira de gestão de negócios, 18(59), 43-66.

Van de Ven, A. H. (1986). Central problems in the management of innovation. Management science, 32(5), 590-607. doi.org/10.1287/mnsc.32.5.590

Veloso, A., Roque, H. \& Ferreira, A.T. (2016). Os efeitos da alteração da relação de emprego nas Unidades de Saúde Familiar: a perspectiva dos profissionais de saúde. Revista E-Psi.6(2), 96-111.

Yu, C.Y. (2002). Evaluating cutoff criteria of model fit indices for latent variable models with binary and continuous outcomes. PhD, University of California, Los Angeles 


\section{Conflicts of interest:}

The authors have no conflict of interest to declare

\section{Copyrights:}

RBGN owns the copyrights of this published content

\section{Plagiarism analysis}

RBGN performs plagiarism analysis on all its articles at the time of submission and after approval of the manuscript using the iThenticate tool.

\section{Authors:}

1. Ana Veloso, PhD in Work and Organizational Psychology, University of Minho, Braga, Portugal.

E-mail: alveloso@psi.uminho.pt

2. Ana Teresa, PhD in Work and Organizational Psychology, Polytechnic of Viana do Castelo, School of Technology and Management, Viana do Castelo, Portugal.

E-mail: ateresaferreira@estg.ipvc.pt

3. Hugo Roque, Master in Psychology, University of Minho, Braga, Portugal.

E-mail: hugoroque1980@gmail.com

4. Jorge Gomes, PhD in Business Administration, University of Lisbon, ISEG Lisbon School of Economics \& Management, Lisbon, Portugal.

E-mail: jorgegomes@iseg.ulisboa.pt

\section{Authors' Contributions}

1. Ana Veloso: Definition of research problem, Development of hypotheses or research questions (empirical studies), Development of theoretical propositions (theoretical work), Theoretical foundation/literature review, Analysis and interpretation of data, Critical revision of the manuscript, Manuscript writing.

2. Ana Teresa: Definition of research problem, Development of hypotheses or research questions (empirical studies), Definition of methodological procedures, Statistical analysis, Analysis and interpretation of data, Critical revision of the manuscript, Manuscript writing.

3. Hugo Roque: Development of hypotheses or research questions (empirical studies), Definition of methodological procedures, Data collection, Statistical analysis, Analysis and interpretation of data.

4. Jorge Gomes: Definition of research problem, Definition of methodological procedures, Critical revision of the manuscript. 